\title{
Rare and Complex Epilepsies from Childhood to Adulthood: Requirements for Separate Management or Scope for a Lifespan Holistic Approach?
}

\author{
Simona Balestrini ${ }^{1,2}\left[\right.$ Renzo Guerrini ${ }^{2}\left[\right.$. Sanjay M. Sisodiya ${ }^{1}(\mathbb{D}$
}

Accepted: 28 September 2021 / Published online: 24 November 2021

(c) The Author(s) 2021

\begin{abstract}
Purpose In this descriptive review, we describe current models of transition in rare and complex epilepsy syndromes and propose alternative approaches for more holistic management based on disease biology.

Recent Findings Previously published guidance and recommendations on transition strategies in individuals with epilepsy have not been systematically and uniformly applied. There is significant heterogeneity in models of transition/transfer of care across countries and even within the same country.

Summary We provide examples of the most severe epilepsy and related syndromes and emphasise the limited data on their outcome in adulthood. Rare and complex epilepsy syndromes have unique presentations and require high levels of expertise and multidisciplinary approach. Lifespan clinics, with no transition, but instead continuity of care from childhood to adulthood with highly specialised input from healthcare providers, may represent an alternative effective approach. Effectiveness should be measured by evaluation of quality of life for both patients and their families/caregivers.
\end{abstract}

Keywords Epileptic encephalopathy $\cdot$ Rare syndrome $\cdot$ Transition $\cdot$ Precision medicine $\cdot$ Lifespan clinics

\section{Introduction}

Transition is the gradual process of planning, preparing, and moving from child to adult health care. This takes years of development, discussion, and implementation and should start at around 12 years of age [1] but will depend on individual circumstances and also on the availability of adult services. The transition period is characterised by a series of socio-demographically and culturally defined events and conditions, based on the natural development of each individual in human societies [2]. Transition has a biology and is underpinned by the dynamics of gene expression, throughout the body, and especially in the brain [3].

Simona Balestrini

simona.balestrini@meyer.it

1 Department of Clinical and Experimental Epilepsy, University College of London (UCL) Queen Square Institute of Neurology, London WC1N 3BG and Chalfont Centre for Epilepsy, London, Bucks, UK

2 Neuroscience Department, Meyer Children's Hospital, European Reference Network ERN EpiCARE, 50139 Florence, Italy
The age of majority is the gateway to adult legal status, presumptively converting legal incapacity to capacity. Today, in many countries the age of majority is eighteen, but it has historically varied from the mid-teens to the midtwenties. Fluctuations in the age of majority have generally accorded with changes in the nature of the capabilities required of society's adult citizens and the age by which individuals tend to attain those capabilities [4].

Transition in epilepsy has been the focus of much attention and concern [5]. Epilepsies in children have significant aetiological and phenotypic heterogeneity, and this has an impact on the transition process. For example, there are epilepsies with onset in childhood or adolescence, in individuals with relatively normal cognition, which typically remit in adolescence or later in adulthood (e.g. benign epilepsy with centrotemporal spikes or childhood absence epilepsy). However, even in drug-responsive epilepsies with no intellectual disability or any other comorbidities, issues may arise during transition, including non-adherence to medication [6] and the use of valproate in females of childbearing age [7]. Matters become further complicated in more rare and complex epilepsy syndromes, especially with comorbid intellectual disability. In these conditions, there are more barriers to 
accessing adult services, including the need for best interest assessments, replacement of regular follow-up appointments with as-required appointment systems, and risk for health problems being either misdiagnosed or overlooked [8]. Transition may thus become more challenging for individuals with complex epilepsy syndromes and everyone involved in their care, and it seems that in many healthcare systems around the world, the provision of a comprehensive transition programme is inadequate. Furthermore, transition in the epilepsies is burdened by the commonplace use of the term "childhood epilepsies", with its inherent implication that some epilepsies affect only children, whilst many severe epilepsies seen in adulthood are of childhood onset but persist into adulthood. In this descriptive review, we first examine the current approaches to transition in rare and complex epilepsy syndromes. We then review the main challenges around transition in these syndromes, giving examples of the most severe ones, and finally propose alternative approaches for more holistic management with examples from other diseases.

\section{Methods}

We searched on PubMed for articles published in English from PubMed inception to Jan 31, 2021. The following search terms were used: "epilepsy + transition", "genetic epilepsy + transition", "epilepsy syndrome + transition", "epilepsy + transition model", "lifespan clinic", "continuity of care", "holistic clinic", "comprehensive health care". Articles were also identified through searches of the authors' own files. The search was restricted to articles published in English. The final reference list was generated based on relevance to the broad scope of this review.

\section{Current Approaches to Transition in Complex Epilepsy Syndromes}

In the epilepsy field, transition of care is often discussed at national and international conferences. In 2016, a symposium on transition in epilepsies was held in Paris, including about 30 paediatric and adult neurologists/epileptologists from several European countries, the USA, and Canada. Three summary papers were subsequently published. [9-11] The first one described five basic themes with an important effect on transition, including brain changes in adolescence such as impulsive pleasure seeking and risky behaviours that may be the result of an imbalance between frontal and limbic maturation, puberty, sexual debut, psychological development, and bone health. Implications of these themes for transition, and some specific interventions to achieve maximum long-term adult independence and quality of life, were discussed. [9] The second paper described the outcome of childhood-onset epilepsy from adolescence to adulthood with the goal of recommending the best approach to transition. Various groups of epilepsy syndromes were discussed: disorders presenting in childhood that may have late- or adult-onset epilepsy (metabolic and mitochondrial disorders), disorders with changing problems in adulthood (tuberous sclerosis complex, Rett syndrome, Dravet syndrome, and autism), epilepsies that change with age (childhood absence epilepsy, juvenile myoclonic epilepsy, West syndrome, and Lennox-Gastaut syndrome), epilepsies that vary in symptoms and severity depending on the age of onset (autoimmune encephalitis, Rasmussen's syndrome), epilepsies with structural aetiology that are less likely to evolve in adulthood, and childhood-onset epilepsies with a risk of later adulthood cerebrovascular disease and dementia [10]. The third paper focused on treatment issues including drugs unfamiliar to adult epilepsy specialists or without licenced indications for adults, optimisation/continuation of treatment in adulthood, treatment of comorbidities, and adherence issues [11].

Current approaches to transition for people with complex epilepsy syndromes vary. We review approaches in different countries and healthcare systems, showing that adoption of recommendations of the reports from the 2016 Paris symposium has been limited. We then consider the practical issues that need to be addressed, following up on those recommendations but also including some independent aspects.

In the UK, there are four avenues for ongoing care of young people aged 16-19 with epilepsy: remaining under paediatric services; discharge to the sole care of the general practitioner (GP); transfer to an adult neurologist or physician who does not necessarily have special expertise in epilepsy; care in a dedicated epilepsy transition service where specific adolescent and adult issues can be raised and discussed in an appropriate setting [12]. The first reported transition clinic for young people in the UK was established in 1991 in Liverpool [13].

In Italy, there are various models that slightly differ across the regional healthcare systems. In general, for drugresistant and complex epilepsy syndromes, joint assessments by the paediatric and adult neurologist for a few visits are recommended [14]. However, it is not uncommon that for rare syndromes, continued follow-up into adulthood by the child neurologists is permitted on an individual basis in the context of a "continuity of care" plan detailing why discontinuation of a longstanding patient/team-physician relationship would be disadvantageous to the patient.

In France, at a centre for rare epilepsies in Paris, a transition programme was established in 2005 , involving a single, dedicated adult neurologist taking over continuing care as young people with severe epilepsy and intellectual disability grew into adults [15]. Issues to be addressed included 
sexual maturation in young adults with cognitive disabilities, psychogenic seizures during stressful developmental stages in adolescence and young adulthood, and care of specific epilepsy syndromes that persist into adulthood. The process included a transfer summary from the paediatric epilepsy service plus complete access to all of the paediatric medical records. After the implementation of the transition programme, a survey for families of patients with Dravet syndrome (DS) showed success in filling the gap between paediatric and adult care systems [16]. Nevertheless, a recent survey conducted in France showed poor knowledge of published recommendations on transition in epilepsy and very rare use of a structured transition programme among paediatric and adult neurologists [17].

In Germany, a concept for a diagnosis-independent transition programme was designed in 2008 and involved health insurance agencies at an early stage [18]. The programme started with patients with epilepsy or type 1 diabetes in the Berlin/Brandenburg region and three health insurance agencies. Three groups were delineated, according to the perceived degree of support required. The medical societies of paediatrics, internal medicine, and neurology have agreed on this programme as the basis of transition and support its use in regular health care. In 2013, the programme became a partner in the modular education system ModuS, which is offered to adolescents with chronic diseases and their parents [19].

In Canada, where there is a universal healthcare system, very few formal transition/transfer programmes exist for children moving to adult epilepsy care. A transition clinic was set up in Halifax, Nova Scotia, which was attended by a paediatric neurologist, adult epileptologist, and an adult epilepsy nurse specialist. Before the clinic appointment, the paediatric neurologist prepared a detailed written summary of the epilepsy issues, and the family prepared a written summary of the psychosocial issues. The entire team extensively reviewed these during the first visit; subsequently, there was one further follow-up visit with the same team before the final move to the adult clinic. When two of the key physicians retired from clinical practice, the structure of this clinic did not persist [20]. In Edmonton, Alberta, another epilepsy transition programme was established, run exclusively by the epilepsy nurse specialists from both paediatric and adult care. The paediatric epileptologist provided a referral letter to the adult epileptologist. The family and patient then met with the adult and paediatric epilepsy nurses and reviewed a number of key transition/transfer themes at one or more visits. Subsequently, the patient ( \pm parents) met the adult epileptologist for ongoing care. A questionnaire assessment suggested that families strongly endorsed this process [21]. Some Canadian data about the adult outcome of children with epilepsy indicate that major social difficulties are common and not easily addressed in the adult healthcare system. A key issue, seen in a number of healthcare systems, is that children with intellectual disabilities and epilepsy are unlikely to be seen or followed by an adult neurologist [15].

There is significant heterogeneity in models of transition/transfer of care even within the same country. There is absence of evidence of the effectiveness for any specific model; neither is it known whether having a transition policy in place translates into any measurable benefit, and it seems that the main issues around transition often remain unaddressed.

There is increasing awareness that healthcare systems should introduce specific changes in order to achieve successful transition from paediatric to adult care for adolescents with chronic conditions, evaluate the short- and longterm outcomes of various transition strategies, and identify those which deserve widespread implementation [22, 23].

Despite various clinical recommendations in Western countries for transition of adolescents with chronic health conditions and special needs [24-26], and some targeted efforts in the epilepsy field [9-11], we still lack a systematic strategy that is sensitive to local circumstances, healthcare systems, and cultural identities.

\section{The Main Challenges Around Transition in Complex Epilepsy Syndromes}

Individual complex epilepsy syndromes are rare but, being numerous, collectively account for an important segment of epilepsy care. In addition, they pose particular issues not often encountered with many more common epilepsy syndromes in which typically comorbidities, in particular intellectual disability, are less prevalent and less severe.

In most secondary care hospitals across the UK, epilepsy in children and young people is managed by paediatricians with expertise in epilepsy and epilepsy nurse specialists, with selective input from tertiary-based paediatric neurologists for drug-resistant epilepsies. However, discussions around independence, sexual health, career choices, and several other aspects often do not take precedence and are perceived as inappropriate in the presence of parents [12]. In addition, during paediatric care, the young person may not have had much input from the family doctor, GP or paediatrician, or other primary care professionals, who then usually become the first point of contact for a young person in the community. This can cause the young person or the family to feel they are no longer receiving specialist care, and there may be difficulties in establishing a relationship with the primary care team in the longer term [12]. In comparison, in the adult setting the young person is likely to be seen alone within a structured consultation. They may have less frequent follow-up visits, and the onus is on the 
young person to seek help independently ad hoc, requiring the young person to have good knowledge of their condition and treatment and recognising when they need help [20]. These changes may have an adverse effect on the care of a young person with intellectual and other disabilities. Adult healthcare professionals may not feel adequately trained to communicate with and look after young people with complex neurological disorders and moderate to severe cognitive impairment. For individuals with cognitive disability, there are additional legal issues, the need for capacity assessment, and best interest decision-making related to clinical management and treatments. Young adults lacking capacity will need an advocate to be responsible for consenting to assessment and treatment, e.g. when inpatient admission is required and an adult ward may not be able to cater for the nuances of care in young people with complex epilepsy and disabilities, who may sometimes carry over into adulthood typical childhood features of the condition.

Treatment is often complex in rare epilepsy syndromes. Optimisation of treatment during transition should be considered, to minimise the long-term side effects of antiseizure drugs, and also before pregnancy to balance the risk of teratogenicity and seizure control [27].

Based on the existing literature and on our own experience, we propose an empirical classification of the main issues around transition into four categories, with a large degree of overlap (Fig. 1): age-related (e.g. independence, puberty, sexuality, psychological development and behavioural changes, bone health), condition-related (e.g. continuity of expertise in clinical management, capacity assessment, clinical course over time, mental health disturbances, and comorbidities), medical needs (e.g. frequency of follow-up visits, consenting to assessment/treatment, treatment optimisation, use of unlicenced drugs, treatment of comorbidities, adherence issues), and social needs (e.g. driving, employment, use of alcohol and recreational drugs, psychological aspects related to independence and stigma, relationships, sexual activity). All the main issues around transition may ultimately affect quality of life. In fact, low quality of life is often described in the transition-aged population, and this is due not only to ongoing seizures, but mental health disturbances and multiple other factors may play a role [28] (Fig. 1).

The roles of families and carers need to be taken into account in chronic conditions associated with disabilities. Parents play a crucial role in transition, and they can often feel unprepared, with limited awareness of adult services, and with limited information on their children's long-term outcomes and future needs [29, 30]. Transition can be a considerable source of parental stress, leading one review

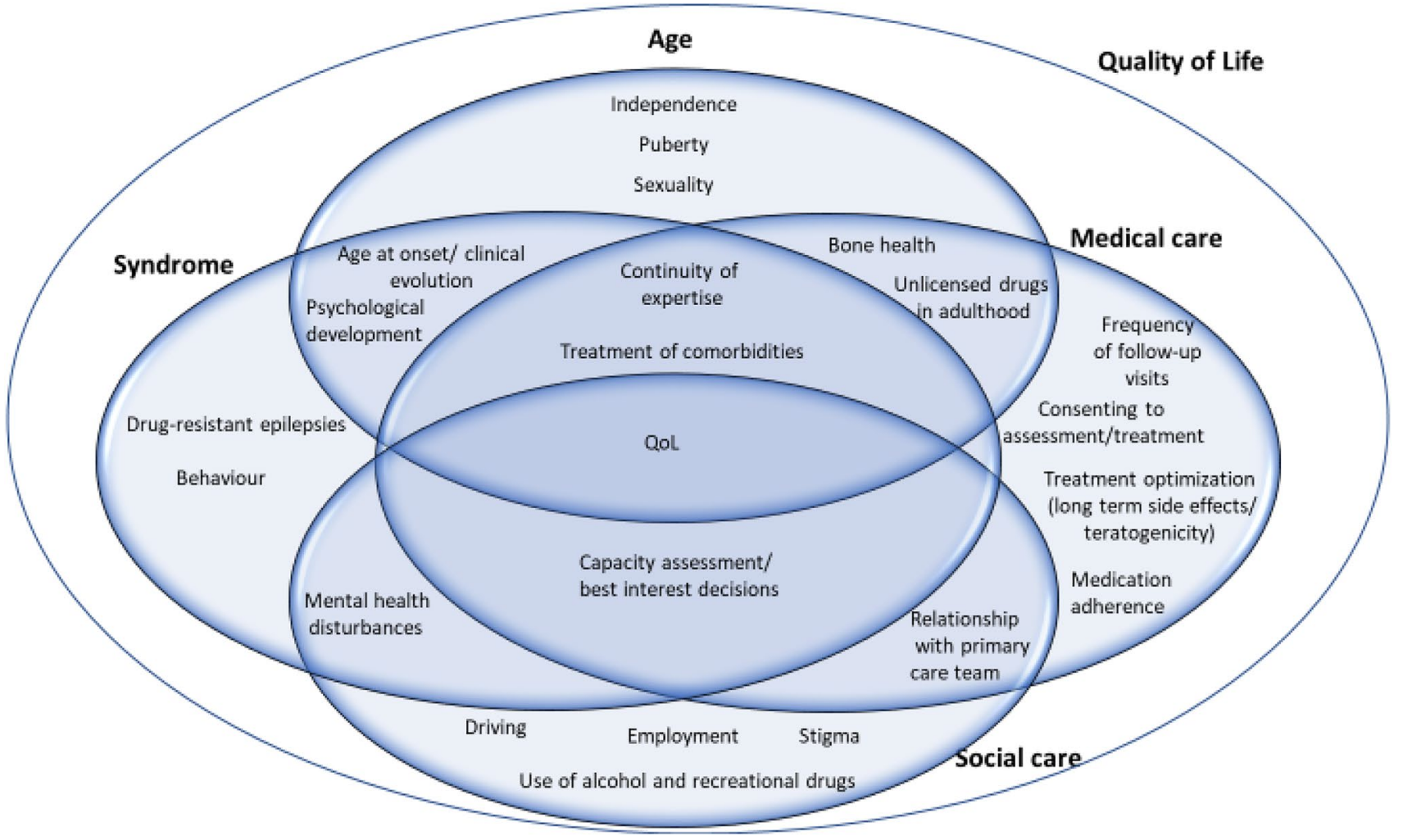

Fig. 1 Venn diagram illustrating the main challenges around transition in complex epilepsy syndrome. The multiple issues are related with age, the specific underlying syndrome, and medical and social care needs 
to conclude that more evidence is "needed for the development of anticipatory guidance to assist parents as their children transition into adulthood" [29]. A recent study of parental perspectives during transition has highlighted that parental roles were perceived as "time consuming, stressful, and unrelenting but necessary to protect children from harm in the face of multiple risks and uncertainties". Conversely, protective strategies were also perceived to hinder adolescent development, family functioning, and their own development as midlife adults [31]. Recommendations were provided for working with parents and young people to manage the risks and uncertainties associated with their condition, as part of routine transitional care [31].

The most severe end of the spectrum of complex epilepsy syndromes includes early-onset developmental and epileptic encephalopathies (DEEs). These are a heterogeneous group of disorders characterised by treatment-refractory seizures and a significant degree of comorbidity including global developmental delay or regression, intellectual disability, movement disorders, autism spectrum disorders, behavioural issues [32], and often with extra-neurological involvement. The aetiology of DEEs is most often genetic, i.e. due to de novo dominant mutations, but X-linked and autosomal recessive forms can also present in neonates. There are high genetic heterogeneity and marked phenotypic pleiotropy. There are also a few exceptions with non-genetic aetiology (e.g. hypoxic-ischemic encephalopathies, postinfectious disorders). The majority of genetic diagnoses are currently made in childhood [33], whilst adults with DEEs often remain undiagnosed due to reduced access to next-generation sequencing, a long history of epilepsy and complex treatment potentially masking syndromic features, and lack of accurate information on early history [34, 35].

Data on survival and outcome in adulthood are lacking for most DEEs. From a phenotypic perspective, the recognition of an electroclinical phenotype may sometimes provide some information on clinical management and prognosis. We provide below an overview, with further details presented in Table 1, of the available prognostic data on electroclinical epilepsy syndromes which may inform the transition process.

Understanding the natural history of disease and identification of prognostic factors are crucial to predict long-term outcomes, to adopt preventative strategies, and to develop disease-modifying treatments. However, our knowledge is still very limited especially in relation to outcome of rare genetic epilepsy syndromes. We can only speculate that multiple factors contribute to disease course, including brain development, specific gene abnormality and associated neurophysiological dysfunction, changes in gene expression over time, role of modifier genes, and also clinical factors such as seizure frequency and behavioural disturbances.[65••] We note that the latter do not always show a linear correlation with outcome; e.g. in DS, the outcome in adulthood is generally poor although epilepsy severity and behavioural abnormalities tend to decrease over time.[49•]

With the advent of next-generation sequencing, more and more gene mutations are being identified as the cause of DEEs and other complex epilepsy syndromes. As a consequence, we are hoping to switch from a syndrome-based description of clinical phenomenology to a more specific understanding based on pathophysiology. Likewise, empirical treatment approach based on the electroclinical phenotype will likely be gradually substituted by an algorithmbased treatment approach aiming to reverse or inhibit the neurophysiological dysfunction caused by the genetic defect [66]. However, such precision medicine treatments are currently available only for a minority of genetic epilepsies, and most patients are still treated on a trial-and-error process. Equally, our understanding of pathophysiological mechanisms and disease course remains very limited for many rare genetic epilepsy syndromes, where our current clinical practice is still mostly grounded on electroclinical phenotypes. The latter are much less defined in adulthood, and in general the concept of DEE/EE is generally less well-defined in older patients. In fact, most studies investigating clinical features and treatment response rely on paediatric data, although obviously appropriate treatment strategies are also required for adults where management becomes even more complicated due to comorbidities and disease evolution.

Identification of a genetic diagnosis may lead to treatment changes with subsequent clinical improvement at any age, for example, withdrawal of sodium channel blockers in DS [47] or creatine supplementation in cerebral creating deficiency type I. [67] However, there are individuals where the causative role of gene mutation is more difficult to establish, [68] or where the putative "precision treatment" is ineffective [69•], or where there are no direct treatment implications following genetic diagnosis.

Among the multiple factors that may play a role in the natural history of complex genetic epilepsy syndromes, gene expression and epigenetic mechanisms probably feature. For some genes, we know that they continue to be highly expressed in the adult human brain, but we do not know how this relates to clinical outcome [70]. There are some suggestions that differential developmental expression pattern of sodium channel genes may influence age at clinical onset and disease course $[69 \bullet, 71]$. To our knowledge, there are no data on the influence of epigenetic mechanisms on the course of complex epilepsy syndromes.

Overall, these examples of genetic disorders with phenotypic heterogeneity and widely variable age at onset provide a strong indication that clinical discontinuity of care between paediatric and adult medicine, although to some extent unavoidable in many current health systems, would 


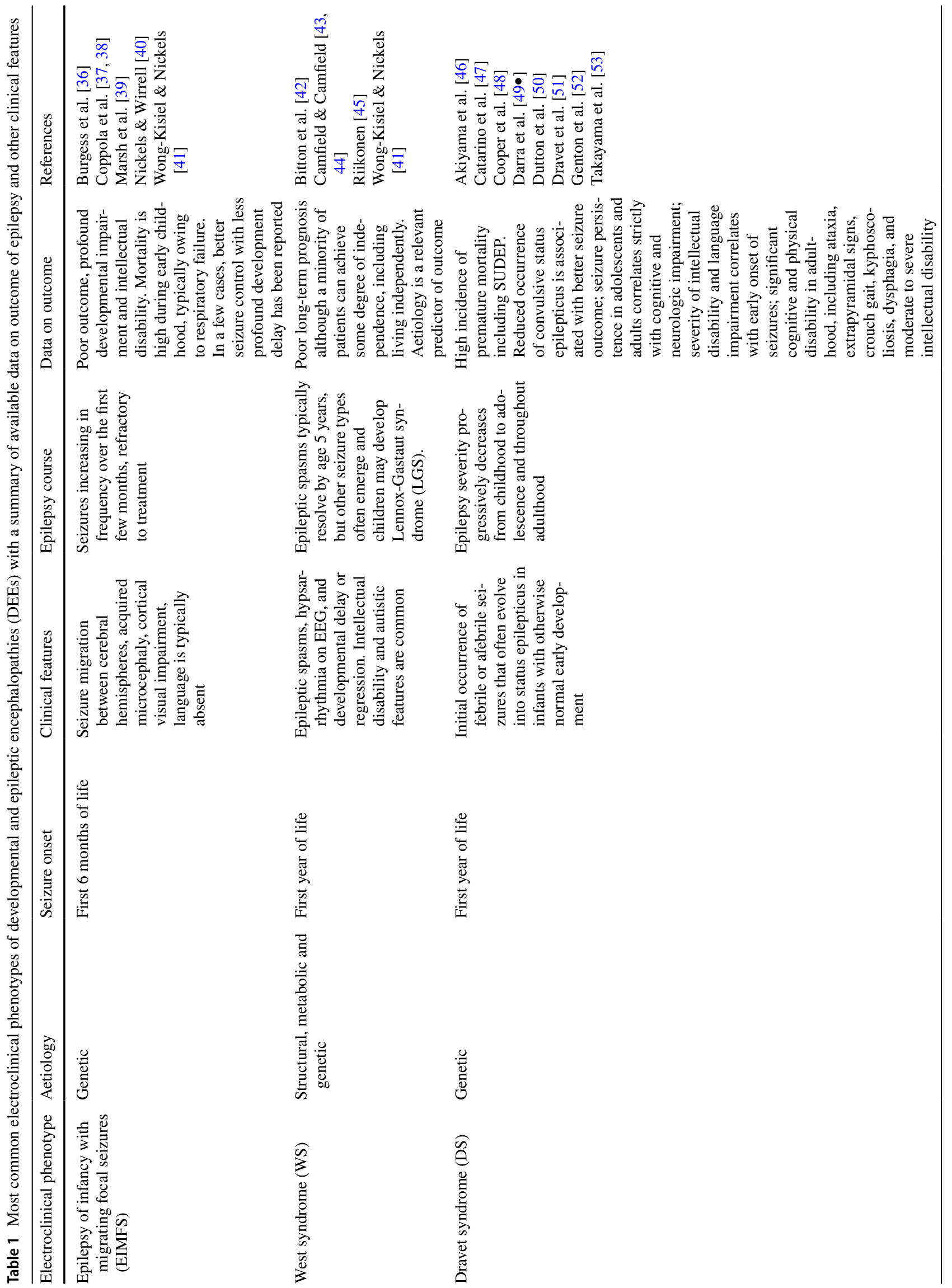




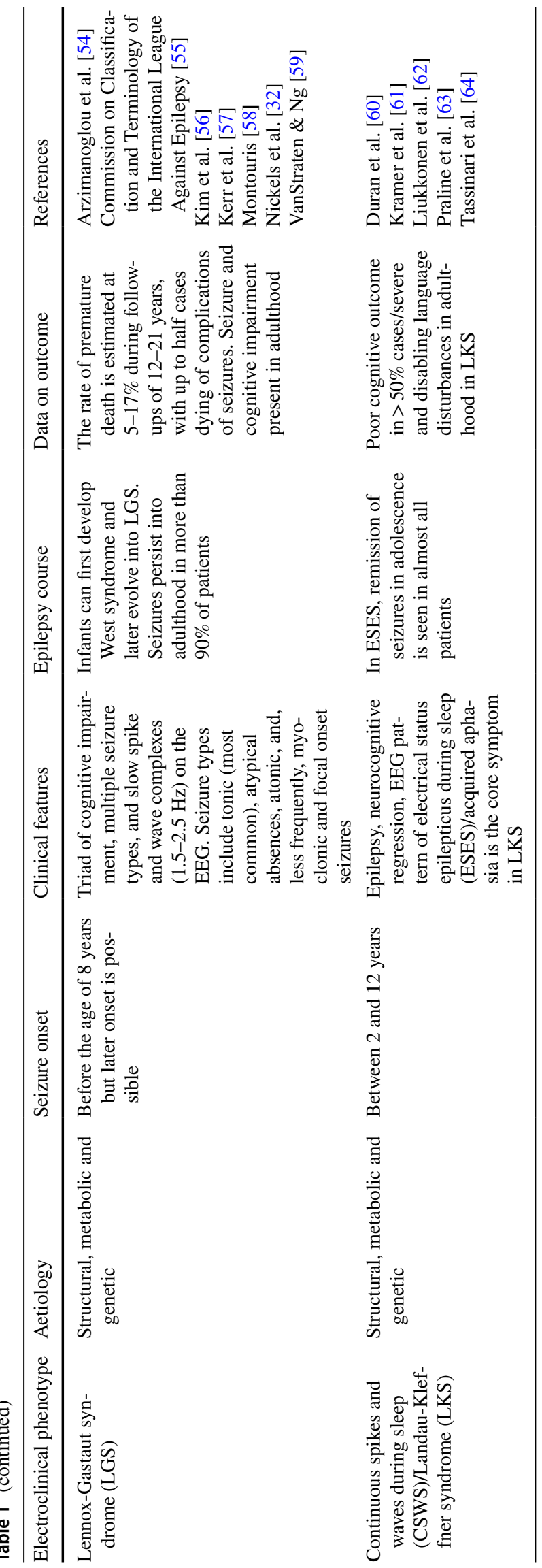

result in oversimplified approaches and detrimental effects on patient care.

\section{Lifespan Clinics as an Alternative Healthcare Model - Examples from Other Diseases}

The current care transition models and recommendations do not address the complexity of rare genetic epilepsy syndromes. There is significant heterogeneity across various transition strategies, and many factors are not taken into account, e.g. the impact of social and cultural environment on chronic health conditions [72]. The main weaknesses of existing models include absence of records of early history; lack of expertise in complex conditions such as genetic DEEs across adult care services [73-75]; late age at the start of transition programmes [75]; and reduced access to new treatments for adult patients with rare conditions (e.g. clinical trials, drugs licenced only for paediatric treatment, target population for experimental treatment trials, etc.). Furthermore, there are specific aspects of chronic epilepsy syndromes in adults that require dedicated expertise, such as physiological somatic changes in adulthood, ageing, and other organ involvement becoming symptomatic in adulthood.

Lifespan clinics, providing follow-up from disease onset throughout life including childhood and adulthood, are alternative models to manage rare and complex conditions. Examples of a similar approach exist in other chronic health conditions. The medical community has recognised that specialised comprehensive care centres can decrease the morbidity and mortality associated with certain chronic diseases. Reduced hospitalisation, morbidity, and mortality rates have followed with commissioning of specialised centres with multidisciplinary teams for haemophilia and cystic fibrosis [76, 77]. Such approaches with holistic management have also been advocated in complex genetic syndromes such as Tuberous Sclerosis Complex (TSC) [78], where, for example, consensus recommendations on surveillance and management are relevant to the entire lifespan [79]. Lifespan care is already provided by clinical genetics services, often including multidisciplinary team-based approaches [80]. There are also reference centres, physical and virtual, for rare disease [81], including the European Reference Network for Rare Neurological Diseases (ERNRND) which was launched by the European Union to support patients and families affected by rare neurological diseases (RND) and provide specialised knowledge, treatment, and resources. The ERN for rare and complex epilepsies (EpiCARE) includes highly specialised health centres in 24 European countries with expertise in such epilepsies and is organised in work packages and modules that approach clinical and research areas of epilepsy in their entirety as 
a whole, irrespective of age-related issues, with the only exception for neonatal seizures [82].

Given the unique presentations and intricacy of rare and complex epilepsy syndromes in which epilepsy is the main clinical element, we propose here the adoption of lifespan clinics where there is no transition but continuity of care from childhood to adulthood with multidisciplinary and highly specialised input from healthcare providers. The specialist involved should have extensive knowledge of principles of the disease and of existing precision medicine strategies for each rare condition, with facilitated access to treatment options and innovative therapies. The epilepsy nurse specialist, currently in existence only in some countries, could play a key role in lifespan management and in communication with family, primary care providers, and other local services (e.g. pharmacies, social services, rehabilitation centres). This model would also facilitate more comprehensive research programmes on rare diseases and address transition with a more individualised approach without a fixed age for care transfer. Such personalised approaches should aim to a better understanding of the underlying pathophysiological dysfunction, including its association with brain maturation and age-related changes in each specific genetic condition. Multiple barriers could arise in implementing lifespan clinics, including restructuring of medical training and healthcare delivery, variation of regulations across different countries, and lack of expertise bridging paediatric and adult care. New professional roles would be needed bridging childhood course with adult outcome, with appropriate knowledge, skills, attitudes, and organisational support to serve people with disabilities, including expertise in assessing the needs and options for assistive technology, general-use technologies, and home modifications. As rare and complex epilepsy syndromes may require health care from early life to the geriatric phase, multidisciplinary teams will be required, and our holistic approach proposal may be implemented in a stepwise manner starting with patients with the most difficult-to-treat epilepsies. Although this approach would require substantial changes in healthcare provision, there are clear advantages and strengths that would justify its implementation in clinical practice.

\section{Conclusions}

Transition describes "a purposeful, planned process that addresses the medical, psychosocial and educational/ vocational needs of adolescents and young adults with chronic physical and medical conditions as they move from childcentred to adult-oriented health systems" [83]. Current models for transition in epilepsy syndromes are heterogeneous and overall do not seem to be highly effective in addressing the complexity of rare genetic conditions. There are a high risk of adolescents, young adults, or even older adults with intellectual disability, whose clinical presentation maintains characteristics usually seen in the paediatric age, remaining in a grey area with inadequate healthcare provision and subsequent higher risks of morbidity and mortality in adulthood. Lifespan clinics could represent a feasible and effective option for specific rare, complex epilepsy syndromes requiring high level of expertise and multidisciplinary approach. Effectiveness should be measured by reduced rate of morbidity and mortality and improved quality of life for both patients and families/ caregivers. We propose lifespan in alternative to transition clinics as an additional route to promote precision medicine in rare and complex epilepsies [84].

Funding SB was supported by the Muir Maxwell Trust and the Epilepsy Society. Part of this work was undertaken at University College London Hospitals, which received a proportion of funding from the National Institute for Health Research Biomedical Research Centres funding scheme.

\section{Compliance with Ethical Standards}

Conflict of Interest The authors declare that they have no conflict of interest.

Human and Animal Rights This article does not contain any studies with human or animal subjects performed by any of the authors.

Open Access This article is licensed under a Creative Commons Attribution 4.0 International License, which permits use, sharing, adaptation, distribution and reproduction in any medium or format, as long as you give appropriate credit to the original author(s) and the source, provide a link to the Creative Commons licence, and indicate if changes were made. The images or other third party material in this article are included in the article's Creative Commons licence, unless indicated otherwise in a credit line to the material. If material is not included in the article's Creative Commons licence and your intended use is not permitted by statutory regulation or exceeds the permitted use, you will need to obtain permission directly from the copyright holder. To view a copy of this licence, visit http://creativecommons.org/licenses/by/4.0/.

\section{References}

Papers of particular interest, published recently, have been highlighted as:

- Of importance

$\bullet$ Of major importance

1. Andrade DM, Bassett AS, Bercovici E, Borlot F, Bui E, Camfield $\mathrm{P}$, et al. Epilepsy: Transition from pediatric to adult care. Recommendations of the Ontario epilepsy implementation task force. Epilepsia. 2017;58(9):1502-17. 
2. Misleading trajectories: transition dilemmas of young adults in Europe. Journal of Youth Studies. 2001;4(1):101-18.

3. Skene NG, Roy M, Grant SG. A genomic lifespan program that reorganises the young adult brain is targeted in schizophrenia. Elife. 2017;12:6.

4. Adulthood in law and culture [Internet]. 2020. Available from: https://scholarship.law.wm.edu/facpubs/1824

5. Devinsky O. Transition to adult care for children with epilepsy-a call for action. Epilepsia. 2014;55(Suppl 3):54-5.

6. Camfield CS, Berg A, Stephani U, Wirrell EC. Transition issues for benign epilepsy with centrotemporal spikes, nonlesional focal epilepsy in otherwise normal children, childhood absence epilepsy, and juvenile myoclonic epilepsy. Epilepsia. 2014;55(Suppl 3):16-20.

7. Gov.UK Valproate use by women and girls. 2018 [Internet]. [cited 2020 Dec 2]. Available from: https://www.gov.uk/guida nce/valproate-use-by-women-and-girls\#toolkit.

8. Heslop P. Bridging the divide at transition: what happens for young people with learning difficulties and their families? Kidderminster [England: BILD Publications; 2002.

9. Camfield P, Camfield C, Busiah K, Cohen D, Pack A, Nabbout $\mathrm{R}$. The transition from pediatric to adult care for youth with epilepsy: basic biological, sociological, and psychological issues. Epilepsy Behav. 2017;69:170-6.

10. Nabbout R, Andrade DM, Bahi-Buisson N, Cross H, Desquerre I, Dulac O, et al. Outcome of childhood-onset epilepsy from adolescence to adulthood: transition issues. Epilepsy Behav. 2017;69:161-9.

11. Nabbout R, Camfield CS, Andrade DM, Arzimanoglou A, Chiron C, Cramer JA, et al. Treatment issues for children with epilepsy transitioning to adult care. Epilepsy Behav. 2017;69:153-60.

12. Iyer A, Rajendran S. Epilepsy: addressing the transition from pediatric to adult care. AHMT. 2016;7:77-87.

13. Appleton RE. Transition from paediatric clinic to the adult service. J R Soc Med. 2001;94(10):554.

14. Percorso assistenziale per la presa in carico delle persone con epilessia, Toscana, 2019 [Internet]. Available from: https:// www.regione.toscana.it/documents/10180/23792978/alleg atoa+decisione+12_2019+-+PDTA_Epilessie.pdf/8f8b446223d4-abbe-b12a-b69d6a539780?t=1578657587030

15. Carrizosa J, An I, Appleton R, Camfield P, Von Moers A. Models for transition clinics. Epilepsia. 2014;55(Suppl 3):46-51.

16. Kuchenbuch M, Chemaly N, Chiron C, Dulac O, Nabbout R. Transition and transfer from pediatric to adult health care in epilepsy: a families' survey on Dravet syndrome. Epilepsy Behav. 2013;29(1):161-5.

17. Nabbout R, Teng T, Chemaly N, Breuillard D, Kuchenbuch M. Transition of patients with childhood onset epilepsy: perspectives from pediatric and adult neurologists. Epilepsy Behav. 2020;104(Pt A):106889.

18. Berliner Transitions Programm [Internet]. [cited 2020 Sep 30]. Available from: http://www.drk-kliniken-berlin.de/westend/ krankenhaus-westend/berliner-transitionsprogramm/

19. Patientenschulung-kompas.de. [Internet]. Available from: http:// www.patientenschulung-kompas.de/t_main.php.

20. Camfield P, Camfield C, Pohlmann-Eden B. Transition from pediatric to adult epilepsy care: a difficult process marked by medical and social crisis. Epilepsy Curr. 2012;12(Suppl 3): $13-21$

21. Jurasek L, Ray L, Quigley D. Development and implementation of an adolescent epilepsy transition clinic. J Neurosci Nurs. 2010;42(4):181-9.
22. Suris J-C, Akre C. Key elements for, and indicators of, a successful transition: an international Delphi study. J Adolesc Health. 2015;56(6):612-8.

23. Mazur A, Dembinski L, Schrier L, Hadjipanayis A, Michaud P-A. European Academy of Paediatric consensus statement on successful transition from paediatric to adult care for adolescents with chronic conditions. Acta Paediatr. 2017;106(8):1354-7.

24. Intercollegiate Working Party On Adolescent Health. Bridging the gaps: health care for adolescents bridging the gaps health care for adolescents [Internet]. Available from: http://rcpch.adlib hosting.com/files/Bridging\%20the\%20Gaps\%20-\%20Health\% 20Care\%20for\%20Adolescents\%202003-06.pdf

25. Kaufman M, Pinzon J, Canadian Paediatric Society, Adolescent Health Committee. Transition to adult care for youth with special health care needs. Paediatrics \& Child Health. 2007;12(9):785-8.

26. White PH, Cooley WC, TRANSITIONS CLINICAL REPORT AUTHORING GROUP, AMERICAN ACADEMY OF PEDIATRICS, AMERICAN ACADEMY OF FAMILY PHYSICIANS, AMERICAN COLLEGE OF PHYSICIANS. Supporting the health care transition from adolescence to adulthood in the medical home. Pediatrics. 2018;142(5).

27. Chiron C, An I. Pharmacology aspects during transition and at transfer in patients with epilepsy. Epilepsia. 2014;55(Suppl 3):8-11.

28. Healy SA, Fantaneanu TA, Whiting S. The importance of mental health in improving quality of life in transition-aged patients with epilepsy. Epilepsy Behav. 2020;112:107324.

29. Betz CL, Nehring WM, Lobo ML. Transition needs of parents of adolescents and emerging adults with special health care needs and disabilities. J Fam Nurs. 2015;21(3):362-412.

30. Heath G, Farre A, Shaw K. Parenting a child with chronic illness as they transition into adulthood: A systematic review and thematic synthesis of parents' experiences. Patient Educ Couns. 2017;100(1):76-92.

31. Shaw KL, Baldwin L, Heath G. 'A confident parent breeds a confident child': Understanding the experience and needs of parents whose children will transition from paediatric to adult care. J Child Health Care. 2020;30:1367493520936422.

32. Nickels KC, Zaccariello MJ, Hamiwka LD, Wirrell EC. Cognitive and neurodevelopmental comorbidities in paediatric epilepsy. Nat Rev Neurol. 2016;12(8):465-76.

33. Rochtus A, Olson HE, Smith L, Keith LG, El Achkar C, Taylor A, et al. Genetic diagnoses in epilepsy: the impact of dynamic exome analysis in a pediatric cohort. Epilepsia. 2020;61(2):249-58.

34. Piña-Garza JE, Chung S, Montouris GD, Radtke RA, Resnick T, Wechsler RT. Challenges in identifying Lennox-Gastaut syndrome in adults: a case series illustrating its changing nature. Epilepsy Behav Case Rep. 2016;5:38-43.

35. Silvennoinen K, Martins Custodio H, Balestrini S, Rugg-Gunn F, England Research Consortium G, Sisodiya SM. Complex epilepsy: it's all in the history. Pract Neurol. 2020 Oct 17; practneurol-2020-002522.

36. Burgess R, Wang S, McTague A, Boysen KE, Yang X, Zeng Q, et al. The Genetic Landscape of Epilepsy of Infancy with Migrating Focal Seizures. Ann Neurol. 2019;86(6):821-31.

37. Coppola G, Plouin P, Chiron C, Robain O, Dulac O. Migrating partial seizures in infancy: a malignant disorder with developmental arrest. Epilepsia. 1995;36:1017-24.

38. Coppola G. Malignant migrating partial seizures in infancy: an epilepsy syndrome of unknown etiology. Epilepsia. 2009;50(Suppl 5):49-51.

39. Marsh E, Melamed SE, Barron T, Clancy RR. Migrating partial seizures in infancy: expanding the phenotype of a rare seizure syndrome. Epilepsia. 2005;46(4):568-72. 
40. Nickels KC, Wirrell EC. Cognitive and Social Outcomes of Epileptic Encephalopathies. Semin Pediatr Neurol. 2017;24(4):264-75.

41. Wong-Kisiel LC, Nickels K. Electroencephalogram of agedependent epileptic encephalopathies in infancy and early childhood. Epilepsy Res Treat. 2013;2013:743203.

42. Bitton JY, Demos M, Elkouby K, Connolly M, Weiss SK, Donner EJ, et al. Does treatment have an impact on incidence and risk factors for autism spectrum disorders in children with infantile spasms? Epilepsia. 2015;56(6):856-63.

43. Camfield P, Camfield C. Long-term prognosis for symptomatic (secondarily) generalized epilepsies: a population-based study. Epilepsia. 2007;48(6):1128-32.

44. Camfield C, Camfield P. Twenty years after childhood-onset symptomatic generalized epilepsy the social outcome is usually dependency or death: a population-based study. Dev Med Child Neurol. 2008;50:859-63.

45. Riikonen R. Long-term otucome of West syndrome: a study of adults with a history of infantile spasms. Epilepsia. 1996;37(4):367-72.

46. Akiyama M, Kobayashi K, Yoshinaga H, Ohtsuka Y. A longterm follow-up study of Dravet syndrome up to adulthood. Epilepsia. 2010;51:1043-52.

47. Catarino CB, Liu JYW, Liagkouras I, Gibbons VS, Labrum RW, Ellis R, et al. Dravet syndrome as epileptic encephalopathy: evidence from long-term course and neuropathology. Brain. 2011;134(Pt 10):2982-3010.

48. Cooper MS, Mcintosh A, Crompton DE, McMahon JM, Schneider A, Farrell K, et al. Mortality in Dravet syndrome. Epilepsy Res. 2016;128:43-7.

49.• Darra F, Battaglia D, Dravet C, Patrini M, Offredi F, Chieffo D, et al. Dravet syndrome: early electroclinical findings and long-term outcome in adolescents and adults. Epilepsia. 2019;60(Suppl 3):S49-58. Retrospective study of two independent cohorts of adolescents and adults with Dravet syndrome showing unfavourable outcome in most cases, albeit with an overall decrease of epilepsy severity in adulthood.

50. Dutton SBB, Dutt K, Papale LA, Helmers S, Goldin AL, Escayg A. Early-life febrile seizures worsen adult phenotypes in Scn1a mutants. Exp Neurol. 2017;293:159-71.

51. Dravet C, Bureau M, Oguni H, Fukuyama Y, Çokar O. Severe myoclonic epilepsy in infancy (Dravet syndrome). In: Roger J, Bureau M, Dravet Ch, Genton P, Tassinari CA, Wolf P (eds) Epileptic syndromes in infancy, childhood and adolescence, 4th edn. John Libbey Eurotext Ltd, Montrouge, 2005; 89-113.

52. Genton P, Velizarova R, Dravet C. Dravet syndrome: the longterm outcome. Epilepsia. 2011;52(Suppl 2):44-9.

53. Takayama R, Fujiwara T, Shigematsu H, Imai K, Takahashi Y, Yamakawa K, et al. Long-term course of Dravet syndrome: a study from an epilepsy center in Japan. Epilepsia. 2014;55(4):528-38.

54. Arzimanoglou A, French J, Blume WT, Cross JH, Ernst JP, Feucht M, et al. Lennox-Gastaut syndrome: a consensus approach on diagnosis, assessment, management, and trial methodology. Lancet Neurol. 2009;8(1):82-93.

55. Commission on Classification and Terminology of the International League Against Epilepsy. Proposal for revised classification of epilepsies and epileptic syndromes. Epilepsia. 1989;30(4):389-99.

56. Kim HJ, Kim HD, Lee JS, Heo K, Kim DS, Kang HC. Longterm prognosis of patients with Lennox-Gastaut syndrome in recent decades. Epilepsy Res. 2015;110:10-9.

57. Kerr M, Kluger G, Philip S. Evolution and management of Lennox-Gastaut syndrome through adolescence and into adulthood: are seizures always the primary issue? Epileptic Disord. 2011;13(Suppl 1):S15-26.
58. Montouris GD. Rational approach to treatment options for Lennox-Gastaut syndrome. Epilepsia. 2011;52(Suppl 5):10-20.

59. VanStraten AF, Ng YT. Update on the management of LennoxGastaut syndrome. Pediatr Neurol. 2012;47(3):153-61.

60. Duran MH, Guimarães CA, Medeiros LL, Guerreiro MM. Landau-Kleffner syndrome: long-term follow-up. Brain Dev. 2009;31(1):58-63.

61. Kramer U, Sagi L, Goldberg-Stern H, Zelnik N, Nissenkorn A, Ben-Zeev B. Clinical spectrum and medical treatment of children with electrical status epilepticus in sleep (ESES). Epilepsia. 2009;50(6):1517-24.

62. Liukkonen E, Kantola-Sorsa E, Paetau R, Gaily E, Peltola M, Granström ML. Long-term outcome of 32 children with encephalopathy with status epilepticus during sleep, or ESES syndrome. Epilepsia. 2010;51(10):2023-32.

63. Praline J, Hommet C, Barthez MA, Brault F, Perrier D, Passage GD, et al Outcome at adulthood of the continuous spike-waves during slow sleep and Landau-Kleffner syndromes. Epilepsia. 2003;44(11):1434-40.

64. Tassinari CA, Rubboli G, Volpi L, Meletti S, d'Orsi G, Franca $\mathrm{M}$, et al. Encephalopathy with electrical status epilepticus during slow sleep or ESES syndrome including the acquired aphasia. Clin Neurophysiol. 2000;111(Suppl 2):S94-102.

65.• Kotulska K, Kwiatkowski DJ, Curatolo P, Weschke B, Riney $\mathrm{K}$, Jansen F, et al. Prevention of epilepsy in infants with tuberous sclerosis complex in the EPISTOP trial. Ann Neurol. 2021;89(2):304-14. Multicentre randomised controlled trial which showed that preventive treatment with vigabatrin was safe and modified the natural history of seizures in tuberous sclerosis complex, reducing the risk and severity of epilepsy.

66. Balestrini S, Sisodiya SM. Treatment of epileptic encephalopathies. Curr Pharm Des. 2017;23(37):5667-90.

67. Stern WM, Winston JS, Murphy E, Cross JH, Sander JW. Guanidinoacetate methyltransferase (GAMT) deficiency: a rare but treatable epilepsy. Pract Neurol. 2017;17(3):207-11.

68. Rosti G, Tassano E, Bossi S, Divizia MT, Ronchetto P, Servetti $\mathrm{M}$, et al. Intragenic duplication of KCNQ5 gene results in aberrant splicing leading to a premature termination codon in a patient with intellectual disability. Eur J Med Genet. 2019 Sep;62(9):103555.

69. Mullen SA, Carney PW, Roten A, Ching M, Lightfoot PA, Churilov L, et al. Precision therapy for epilepsy due to KCNT1 mutations: a randomized trial of oral quinidine. Neurology. 2018;90(1):e67-72. Single-centre, placebo-controlled, crossover trial of oral quinidine in six patients with sleep-related hypermotor epilepsy due to KCNT1 mutation which failed to show efficacy. Dose-limiting cardiac side effects were observed.

70. Cantagrel V, Lossi A-M, Boulanger S, Depetris D, Mattei M-G, Gecz J, et al. Disruption of a new X linked gene highly expressed in brain in a family with two mentally retarded males. J Med Genet. 2004;41(10):736-42.

71. Zaman T, Helbig I, Božović IB, DeBrosse SD, Bergqvist AC, Wallis K, et al. Mutations in SCN3A cause early infantile epileptic encephalopathy. Ann Neurol. 2018;83(4):703-17.

72. Institute of Medicine (US) Committee on Assessing Interactions Among Social, Behavioral, and Genetic Factors in Health; Genes, behavior, and the social environment: moving beyond the nature/nurture debate. In: The Impact of Social and Cultural Environment on Health [Internet]. Available from: https://www. ncbi.nlm.nih.gov/books/NBK19924/

73. Both P, Ten Holt L, Mous S, Patist J, Rietman A, Dieleman G, et al. Tuberous sclerosis complex: concerns and needs of patients and parents from the transitional period to adulthood. Epilepsy Behav. 2018;83:13-21. 
74. Bar C, Ghobeira R, Azzi R, Ville D, Riquet A, Touraine R, et al. Experience of follow-up, quality of life, and transition from pediatric to adult healthcare of patients with tuberous sclerosis complex. Epilepsy Behav. 2019;96:23-7.

75. Boyce DM, Devinsky O, Meskis MA. Barriers to transition from pediatric to adult care for patients with Dravet syndrome: a focus group study of caregivers. Epilepsy Behav. 2020;109:107096.

76. Minniti CP, Vichinsky E. Lifespan care in SCD: Whom to transition, the patients or the health care system? Am J Hematol. 2017;92(6):487-9.

77. Bell SC, Mall MA, Gutierrez H, Macek M, Madge S, Davies JC, et al. The future of cystic fibrosis care: a global perspective. Lancet Respir Med. 2020;8(1):65-124.

78. Auvin S, Bissler JJ, Cottin V, Fujimoto A, Hofbauer GFL, Jansen AC, et al. A step-wise approach for establishing a multidisciplinary team for the management of tuberous sclerosis complex: a Delphi consensus report. Orphanet J Rare Dis. 2019;14(1):91.

79. Krueger DA, Northrup H, International Tuberous Sclerosis Complex Consensus Group. Tuberous sclerosis complex surveillance and management: recommendations of the 2012 International Tuberous Sclerosis Complex Consensus Conference. Pediatr Neurol. 2013;49(4):255-65.
80. Battista RN, Blancquaert I, Laberge A-M, van Schendel N, Leduc N. Genetics in health care: an overview of current and emerging models. Public Health Genomics. 2012;15(1):34-45.

81. The portal for rare diseases and orphan drugs [Internet]. Available from: https://www.orpha.net/consor/cgi-bin/Clinics.php? $\operatorname{lng}=\mathrm{EN}$

82. ERN for rare and complex epilepsies (EpiCARE) [Internet]. Available from: https://epi-care.eu/

83. Rosen DS, Blum RW, Britto M, Sawyer SM, Siegel DM, Society for Adolescent Medicine. Transition to adult health care for adolescents and young adults with chronic conditions: position paper of the Society for Adolescent Medicine. J Adolesc Health. 2003;33(4):309-11.

84. Sisodiya SM. Precision medicine and therapies of the future. 021 Mar;62 Suppl 2:S90-S105.

Publisher's Note Springer Nature remains neutral with regard to jurisdictional claims in published maps and institutional affiliations. 